ASTHMA

\title{
Impact of changes in the IOC-MC asthma criteria: a British perspective
}

\author{
J W Dickinson, G P Whyte, A K McConnell, M G Harries
}

Thorax 2005;60:629-632. doi: 10.1136/thx.2004.037499

See end of article for authors' affiliations

....................

Correspondence to: Mr J W Dickinson, English Institute of Sport, Bisham Abbey High Performance Centre, Bisham, $\mathrm{Nr}$ Marlow, Bucks SL7 1RT, UK; john.dickinson@ eis2win.co.uk

Received

11 November 2004 Accepted 29 March 2005
Background: Since 2001 the International Olympic Committee-Medical Commission (IOC-MC) has required athletes using inhaled $\beta_{2}$ agonists to provide clinical evidence of their asthmatic condition. The aim of this study was to compare the reported prevalence of asthma at the 2000 and 2004 Olympic Games in the Great British Olympic team (Team GB).

Methods: Following local ethics committee approval, 271 athletes (165 men) from the 2004 Team GB volunteered and provided written informed consent. An athlete was confirmed asthmatic if he or she had a positive bronchoprovocation or bronchodilator test as defined by the IOC-MC. Pre-Olympic medical forms from the 2000 Team GB were also examined to establish the prevalence of asthma among the members of Team GB at the 2000 Olympic Games.

Results: The prevalence of asthma in the two teams at the 2000 and 2004 Olympic Games was similar (21.2\% and 20.7\%, respectively). In the 2004 Olympic Games 13 of 62 athletes (21.0\%) with a previous diagnosis of asthma tested negative. A further seven with no previous diagnosis of asthma tested positive. Conclusions: The prevalence of asthma within Team GB remained unchanged between 2000 and 2004. The IOC-MC requirement that asthmatic athletes must submit documented evidence of asthma has highlighted that $13(21.0 \%)$ previously diagnosed as asthmatic failed to demonstrate evidence of asthma while seven athletes with no previous history or diagnosis of asthma tested positive. Screening for asthma within elite athletic populations using bronchoprovocation challenges appears warranted to assist athletes in preparing more effectively for major sporting events.
$\mathrm{E}$ xercise induced asthma (EIA) causes expiratory limitation following exercise. It can be triggered by an increase in the volume of "unconditioned" air inspired through the mouth. During increased levels of activity "unconditioned" air cools and dries the upper and lower airways inducing inflammation and smooth muscle contraction leading to bronchial narrowing ${ }^{1}$ that is readily reversible with inhaled short acting $\beta_{2}$ agonists. The prevalence of EIA in athletic populations has been shown to vary between $9 \%$ and $55 \%,{ }^{23}$ depending on the type of sport, diagnostic test used, and environment. Participants in winter sports generally have a higher prevalence of EIA than those engaged in summer sports. $^{4-7}$

A number of studies have shown that therapeutic doses of inhaled short acting $\beta_{2}$ agonists have no performance enhancing effects, ${ }^{8-11}$ yet the International Olympic Committee-Medical Commission (IOC-MC) has stated that a simple notification from the team medical officer stating the athlete has EIA is no longer acceptable. ${ }^{12}$ A more rigorous testing regime including maximal voluntary flow-volume loops is now required..$^{13}$

One of the main reasons the IOC-MC has given for the enhanced level of evidence is an apparent increase in the prevalence of asthmatic athletes since the 1984 Olympic Games. ${ }^{13}$ At the 1984 Los Angles Olympics 11\% of the US Olympic team were using inhalers. ${ }^{14}$ The prevalence of asthma reported within the US team at the 1996 Olympics in Atlanta was $14 \%,{ }^{4}$ and by 1998 at the Winter Olympics in Nagano this figure had reached $17 \% .{ }^{5}$ While there seems to be a progressive rise in EIA within the US Olympic teams, there are limited reports on the prevalence of asthma in the Olympic teams of other nations. What remains unclear is whether the observed increase in the prevalence of asthma in the US teams is an indication of a global trend at the elite athletic level. Further, there are few data available on sport specific prevalence. ${ }^{15}$

Many studies have reported the prevalence of asthma by the sole use of questionnaires and symptoms. ${ }^{4}{ }^{14} 16-19$ This approach, however, is regarded as a poor method of assessment. For example, Rundell et $a l^{20}$ examined the accuracy of symptom based diagnosis compared with an exercise challenge to diagnose EIA in elite winter athletes by comparing results from an asthma symptoms questionnaire with those from exercise challenge. Of the $26 \%$ of participants who tested positive for EIA in response to the exercise challenge, only $40 \%$ of these reported more than one symptom of EIA in the questionnaire. Post-exercise cough was the most common symptom reported by both EIA positive and EIA negative athletes. The high number of false positives and false negatives from questionnaire diagnosis highlights the need for bronchoprovocation tests and supports the IOC-MC requirement for athletes to produce quantitative evidence of their asthma.

The relative paucity of sport specific data examining the prevalence of asthma/EIA, together with the IOC-MC changes in criteria for asthma diagnosis, provide the rationale for this study. The purpose of this study was to compare the prevalence of EIA within the Great British Olympic Team (Team GB) at the 2000 and 2004 Summer Olympic Games, to quantify sport specific differences in the prevalence of EIA, and to examine the implications of changes made in the IOCMC guidelines.

Abbreviations: EIA, exercise induced asthma; $\mathrm{EVH}$, eucapnic voluntary hyperpnoea; $\mathrm{FEV}_{1}$, forced expiratory volume in 1 second 


\begin{tabular}{|c|c|c|c|c|}
\hline & \multicolumn{2}{|c|}{2000} & \multicolumn{2}{|c|}{2004} \\
\hline & $\mathrm{N}$ & No (\%) asthmatic & $\mathrm{N}$ & No $(\%)$ asthmatic \\
\hline Athletics & 28 & $7(25)$ & 58 & $9(16)$ \\
\hline Badminton & 13 & $2(15)$ & 11 & 1 (9) \\
\hline Canoe/kayak & 12 & $1(8)$ & 9 & 1 (11) \\
\hline Cycling & 27 & $12(44)$ & 23 & $9(39)$ \\
\hline Diving & 7 & $3(43)$ & 7 & 1 (14) \\
\hline Gymnastics & 14 & 0 & 9 & 0 \\
\hline Hockey & 31 & $3(10)$ & 16 & $5(31)$ \\
\hline Judo & 10 & $2(20)$ & 8 & 1 (13) \\
\hline Rowing & 41 & $8(20)$ & 36 & $7(19)$ \\
\hline Sailing & 17 & 0 & 18 & 0 \\
\hline Shooting & 6 & 0 & 6 & $1(17)$ \\
\hline Swimming & 41 & $17(41)$ & 36 & 16 (44) \\
\hline Triathlon & 8 & 0 & 6 & 0 \\
\hline Other & 19 & $3(16)$ & 28 & $5(18)$ \\
\hline \multicolumn{5}{|l|}{ Overall } \\
\hline Men & 152 & $29(19.1)$ & 165 & $34(20.6)$ \\
\hline Women & 122 & $29(23.8)$ & 106 & $22(20.8)$ \\
\hline Total & 274 & 58 (21.2) & 271 & $56(20.7)$ \\
\hline
\end{tabular}

\section{METHODS}

\section{Team GB}

Following local ethical committee approval, British athletes ( 165 men, 106 women) selected to compete in the 2004 Team GB were recruited. All athletes were volunteers and provided written informed consent. Athletes were only tested for asthma if they had a previous diagnosis of EIA or reported symptoms of EIA or were referred for testing by a team medical officer.

\section{IOC-MC criteria}

Diagnosis of asthma for the 2004 Team GB members was made according to the IOC-MC requirements, which included a positive bronchodilator or bronchoprovocation test. The IOC-MC criteria for a positive diagnosis in a bronchodilator challenge were met if the forced expiratory volume in l second $\left(\mathrm{FEV}_{1}\right)$ increased by $15 \%$ or more following a therapeutic inhaled dose $(200 \mu \mathrm{g})$ of a short acting $\beta_{2}$ agonist (salbutamol). The IOC-MC criteria for a positive diagnosis in a bronchoprovocation challenge were met if the postchallenge $\mathrm{FEV}_{1}$ fell $10 \%$ or more from the pre-challenge $\mathrm{FEV}_{1}$ measurement. Both bronchodilator and bronchoprovocation responses were assessed using maximal effort flowvolume spirometry, measured with an electronic spirometer that met American Thoracic Society guidelines (MicroLab ML3500, Micro Medical, Rochester, UK). The best of three criteria were applied for selection of recordings.

All asthma drug treatments including inhaled corticosteroids and long acting $\beta_{2}$ agonists were withdrawn for a minimum of 72 hours before each bronchial challenge. Athletes were advised to use short acting $\beta_{2}$ agonists if they required any asthma relief during this period.

\section{Bronchodilator challenge}

The bronchodilator challenge involved measuring maximal voluntary flow-volume loops before and 10 minutes after a therapeutic dose $(200 \mu \mathrm{g})$ of an inhaled $\beta_{2}$ agonist (salbutamol).

\section{Bronchoprovocation challenges}

The bronchoprovocation challenges consisted of either an exercise challenge or eucapnic voluntary hyperpnoea (EVH) challenge. ${ }^{21}$

\section{Exercise}

An exercise challenge involved measuring maximal flowvolume loops before exercise and at 3, 5, 10 and 15 minutes after stopping exercise. The exercise challenges were conducted for a minimum of 4 minutes and were designed to be as sport specific as possible, so could involve running, cycling, rowing or swimming. The target heart rate (HR) during the exercise challenge was $80-90 \%$ of HRmax (220 - age).

\section{Eucapnic voluntary hyperventilation (EVH)}

The EVH challenges involved measuring maximal voluntary flow-volume loops before EVH (best of three) and at 3, 5, 10, and 15 minutes after stopping hyperventilation (single effort). The EVH challenge required the athlete to hyperventilate for 6 minutes at a rate of 30 times their baseline $\mathrm{FEV}_{1}$. To prevent hypocapnia during hyperventilation, subjects inspired a gas mix containing $5 \% \mathrm{CO}_{2}, 21 \% \mathrm{O}_{2}$, and $74 \% \mathrm{~N}_{2} .{ }^{21}$

\section{Prevalence of asthma in 2000 Team GB}

Competitors' medical forms from the 2000 Team GB (120 women, 152 men) were used to obtain the reported prevalence of asthma before the IOC required quantitative evidence of asthma. Data obtained from these forms included the athletes' asthmatic status and event.

\section{Analysis of data}

The prevalence of asthma within each sport for 2000 Team GB and 2004 Team GB is reported descriptively by sport, sex, and overall prevalence.

\section{RESULTS}

Seventy seven athletes who were members of 2004 Team GB were tested for asthma using a test recognised by the IOC. All athletes required to provide evidence of asthma were tested. Sixty two of these athletes had been previously diagnosed with asthma and were prescribed asthma medication; 13 of these $62(21 \%)$ failed to produce a positive test for asthma under IOC criteria. Of the 13 athletes, all reported symptoms of EIA with post exercise cough $(n=10)$, wheezing $(n=10)$, and chest tightness $(n=10)$. In addition to the 62 athletes receiving medication, a further 15 athletes referred by a team medical officer were tested. Seven of these 15 athletes (47\%) had no previous history or diagnosis of asthma tested positive for asthma under IOC guidelines. Four of these seven athletes 
reported symptoms of EIA with post exercise cough $(n=3)$, wheezing $(n=3)$, and chest tightness $(n=3)$ being the most common. The athletes who met the criteria to use asthma medication at the 2004 Olympic Games $(n=56)$ won a total of 17 medals (seven Gold, seven Silver, three Bronze). The athletes who failed to meet the IOC-MC criteria and were subsequently removed from asthma medication $(n=13)$ at the 2004 Olympic Games won a total of two medals (both Gold).

Of the 56 IOC-MC positive athletes, only two provided evidence of asthma through bronchodilator challenge; all the others required a bronchoprovocation challenge. The fall in $\mathrm{FEV}_{1}$ elicited by the positive exercise challenges ranged from $10.5 \%$ to $23.3 \%$. The fall in $\mathrm{FEV}_{1}$ elicited by positive EVH challenges ranged from $10.0 \%$ to $61.3 \%$. All athletes who had a positive bronchoprovocation challenge demonstrated reversibility.

The prevalence of asthma in the British squad at both the 2000 and 2004 Olympic Games is displayed in table 1 by sex, sport, and overall prevalence.

Swimming had the third highest prevalence of asthma in $2000(41 \%)$ and the highest in 2004 (44\%). Other sports in which the prevalence of asthma also remained similar between 2000 and 2004 included canoeing (8\% v 11\%), rowing $(20 \% v 19 \%)$, and cycling (44\% vv 39\%). Sports in which there was a fall in the prevalence of asthma from 2000 to 2004 included athletics (25\% v 16\%), badminton ( $15 \% v$ $9 \%)$, diving $(43 \% \vee 14 \%)$, and judo $(20 \% \vee 13 \%)$. Sports that have seen an increase in the prevalence of asthma from 2000 to 2004 include archery (33\% v 50\%), men's hockey ( $13 \% v$ $31 \%)$, shooting $(0 \% \vee 17 \%)$ and tae kwon do $(0 \% \vee 25 \%)$. Sports that had no asthmatics in either 2000 or 2004 included boxing, gymnastics, modern pentathlon, sailing, tennis, weightlifting, and wrestling.

\section{DISCUSSION}

The main finding of this study was that the prevalence of EIA in Team GB athletes was unchanged between the 2000 and 2004 Olympic Games whereas, within the US Olympic team, it appears to be rising. ${ }^{45}{ }^{14}$ Unfortunately, it is impossible to determine precisely how the diagnoses of asthma in the US Olympic team were made, as they were conducted at a time when a range of different (unspecified) methods were employed. In the case of our own data, $21 \%$ of athletes previously diagnosed with asthma and using inhalers did not meet the IOC-MC criteria. This indicates that a large number of British Olympic athletes were receiving medication for which there was no clinical indication. The percentage of athletes in the 2004 Team GB squad who did not meet IOCMC criteria is similar to the percentage of athletes whose application was declined by the IOC-MC at the 2002 Winter Olympics; ${ }^{13} 29$ of 159 (18\%) of those who submitted an application to use $\beta_{2}$ agonists at the 2002 Winter Olympics were refused by the IOC-MC. We support the IOC-MC contention that a large number of athletes may be misdiagnosed and inappropriately medicated. The new IOCMC asthma/EIA guidelines may therefore improve athlete care.

Despite identifying inappropriately medicated athletes and their subsequent withdrawal from medication, there was no overall change in the prevalence of asthma within Team GB between 2000 and 2004. This outcome is probably due to the identification of the small number $(n=7)$ of athletes with no previous history who had a positive response to bronchoprovocation. If diagnosis in the 2004 team had been based on symptoms alone, then the prevalence rate would have been $27 \%([62+12] / 271)$, which is higher than the actual prevalence rate and higher than the rate reported in 2000 $(21 \%)$. This finding is consistent with previous studies that have shown a continued rise in the prevalence of asthma at Olympic Games. ${ }^{4}{ }^{13} 14$ Our data require substantiation by data from future Olympics using the new IOC-MC criteria.

The results from the present study show that there is variation between sports in the prevalence of asthma in Team GB Olympic teams, with swimming having one of the highest at both the 2000 and 2004 Olympics Games (>40\%). It has been suggested that the high prevalence of asthma in swimmers may be due to the environment in which they train and compete, with a high concentration of chlorine which may act as a potent trigger for EIA. ${ }^{22}{ }^{23}$ Other sports such as figure skating and cross country skiing have also been reported to have a similarly high prevalence of asthma (35\%, and 50\%, respectively), which has been associated with training and competing in cold and dry or polluted environments. ${ }^{64}{ }^{25}$ This suggests that athletes who compete in certain sports may be more susceptible to the development of EIA than others. What is of great concern is that our data indicate that the overall prevalence of asthma is higher in elite athletes than it is in the general UK adult population $(7.8 \%) .^{26}$ The factors underlying this observation require urgent attention since they have implications-not only for elite athletes-but also for the many recreational athletes in the UK and elsewhere.

The small number of athletes within some of the squads (archery, boxing, fencing, modern pentathlon, shooting, tae kwon doe, triathlon) makes it difficult to obtain an accurate impression of the prevalence of EIA/asthma by sport. Indeed, the prevalence data for triathlon appears to be inconsistent with our other findings. At the 2000 and 2004 Olympic Games the Team GB triathlon squad did not have one athlete diagnosed with asthma, yet swimming and cycling were among the sports with the highest prevalence of asthma at both the 2000 and 2004 Olympic Games. It is possible that the absence of triathletes with asthma in Team GB may be due to the small size of the squad and may not be a true representation of triathlon as a whole. Future investigations could overcome this by polling prevalence data from the Olympic teams of several countries. Multicentre data collection is indicated to support collection of prevalence data.

In a unique study by Alaranta et al ${ }^{19}$ sports were classified into four main groups and the prevalence of EIA was reported on the basis of whether the sport was endurance, team, speed/power, or motor skill. The prevalence of EIA was highest in endurance sports $(22.2 \%)$ and team sports (14.5\%) compared with $8.8 \%$ for speed and power sports and $8.2 \%$ for motor skill sports. Unfortunately, the study relied solely on physician diagnosis and it lacked individual sport prevalence data. Our data used recognised EIA tests to gain the prevalence data at the 2004 Olympics and also examined the individual sports. It is difficult to make a direct comparison with the data from the study by Alaranta et al ${ }^{19}$ as sports such as swimming and athletics have many different events ranging from sprinting to endurance events. Subdividing events into groups based on their aerobic requirement seems to suggest that events with a longer exposure to inhalation of "unconditioned" air (such as endurance events) could have a higher prevalence of EIA than events that involve shorter exposure to "unconditioned" air (such as sprint events), supporting the implication of the study by Alaranta et al. ${ }^{19}$ Furthermore, sports/events that take place in environments that have a high potency for triggering EIA (such as dry/polluted air) may have the highest prevalence of asthma regardless of the duration of the activity (for example, winter sports/swimming). This interpretation suggests that the development of EIA may be exacerbated, or even caused, by a process of airway remodelling in response to training and competing in an environment that triggers EIA. This remodelling process may 
occur at different speeds, depending on the individual, type of event, and environment.

The introduction of more rigorous testing procedures for the diagnosis of EIA/asthma resulted in $21 \%$ of athletes who were thought to be EIA positive being confirmed as EIA negative. This rate of misdiagnosis is not as high as that reported by Rundell et $a l^{20}$ in their comparison of questionnaire diagnosis and diagnosis via exercise challenges $(60 \%)$. One of the reasons for this could be the variety of different methods used to diagnose asthma in Team GB athletes in the past. Thus, not all of the athletes who took part in our study would have received a previous diagnosis based on symptoms alone. At present no systematic programme exists for the diagnosis of EIA/asthma in Team GB athletes. Such a programme could reduce the chance of false positive diagnoses and reduce the needless use of medication which may have potentially damaging side effects, such as downregulation of airway $\beta_{2}$ receptors. ${ }^{27}$ Perhaps more importantly, this study identified seven athletes with no previous history or diagnosis of asthma, three of whom reported no symptoms of EIA on questioning. Some of them presented with falls in $\mathrm{FEV}_{1}$ of more than $40 \%$ following EVH challenge. The implications of untreated EIA/ asthma for the performance, health, and wellbeing of these athletes can only be speculated upon and argues strongly for the routine screening of all athletes.

In conclusion, the prevalence of asthma in 2004 Team GB athletes remained similar to that in 2000 Team GB athletes, despite changes in IOC-MC requirements. The improved diagnostic techniques, however, identified a large number of false positive diagnoses and also identified a number of previously unknown asthmatics. These athletes were either removed from unnecessary treatment or placed on appropriate medication, and therefore received an improved level of care. Screening for EIA within elite athletic populations using bronchoprovocation challenges such as EVH and exercise appears warranted, not only to assist athletes in preparing for major sporting events but also to ensure the best possible level of care.

\section{ACKNOWLEDGEMENTS}

The authors are grateful to the European Olympic Committee, UK Sport, British Olympic Medical Trust and Micro Medical Ltd (www.micromedical.co.uk).

\author{
Authors' affiliations \\ J W Dickinson, G P Whyte, English Institute of Sport, Bisham Abbey \\ High Performance Centre, Bisham, Bucks, UK \\ J W Dickinson, G P Whyte, Olympic Medical Institute, Harrow, \\ Middlesex, UK \\ A K McConnell, Brunel University, Uxbridge, Middlesex, UK \\ M G Harries, Northwick Park Hospital, Harrow, Middlesex, UK \\ Competing interests: none declared
}

\section{REFERENCES}

1 Anderson S, Daviskas E. The mechanism of exercise induced asthma is ... J Allergy Clin Immunol 2000;106:453-9.

2 Hallstrand T, Curtis J, Koepsell T, et al. Effectiveness of screening examinations to detect unrecognized exercise-induced bronchoconstriction. J Pediatr 2002;141:343-8.

3 Mannix E, Manfredi F, Farber M. A comparison of two challenge tests for identifying exercise-induced bronchospasm in figure skaters. Chest 1999; 115:649-53

4 Weiler J, Layton T, Hunt M. Asthma in United States Olympic athletes who participated in the 1996 Summer Games. J Allergy Clin Immunol 1998; 102:722-6.

5 Weiler J, Ryan E. Asthma in United States Olympic athletes who participated in the 1998 Olympic Winter Games. J Allergy Clin Immunol 2000;106:267-71

6 Wilber R, Rundell K, Szmedra L, et al. Incidence of exercise-induced bronchospasm in Olympic winter sport athletes. Med Sci Sports Exerc 2000;32:732-7.

7 Rundell K, Wilber R, Szmedra L, et al. Exercise-induced asthma screening of elite athletes: field versus laboratory exercise challenge. Med Sci Sports Exerc 2000:32:309-16

8 Goubault C, Perault M, Leleu E, et al. Effects of inhaled salbutamol in exercising non-asthmatic athletes. Thorax 2001;56:675-9.

9 Collomp K, Candau R, Millet G, et al. Effects of salbutamol and caffeine ingestion on exercise metabolism and performance. Int J Sports Med 2002;23:549-54.

10 Meeuwisse W, McKenzie D, Hopkins S, et al. The effect of salbutamol on performance in elite nonasthmatic athletes. Med Sci Sports Exerc 1992;24:1161-6.

11 Morton A, Joyce K, Papalia S, et al. Is salmeterol ergogenic? Clin J Sport Med $1996: 6: 220-5$

12 Medical Commission of the International Olympic Committee. IOC's medical code. Lausanne: International Olympic Committee, 2002.

13 Anderson S, Fitch K, Perry C, et al. Responses to bronchial challenge submitted for approval to use inhaled beta2-agonists before an event at the 2002 Winter Olympics. J Allergy Clin Immunol 2003;111:45-50.

14 Voy R. The US Olympic Committee experience with exercise-induced bronchospasm, 1984. Med Sci Sports Exerc 1986;18:328-30.

15 Rundell K. Overuse of asthma medication in athletics? Med Sci Sports Exerc 2004;36:925.

16 Nysted W, Harris J, Borgen S. Asthma and wheezing among Norwegian elite athletes. Med Sci Sports Exerc 2000;32:266-70.

17 Turcotte H, Langdeau J, Bowie D, et al. Are questionnaires on respiratory symptoms reliable predictors of airway hyperresponsiveness in athletes and sedentary subjects? J Asthma 2003:40:71-80.

18 Kippelen P, Caillaud C, Coste O, et al. Asthma and exercise-induced bronchoconstriction in amateur endurance-trained athletes. Int J Sports Med 2004;25:130-2.

19 Alaranta A, Alaranta H, Palmu P, et al. Asthma medication in Finnish Olympic athletes: no signs of inhaled $\beta_{2}$-agonist overuse. Med Sci Sports Exerc 2004;36:919-24

20 Rundell K, Im J, Mayers L, et al. Self-reported symptoms and exercise-induced asthma in the elite athlete. Med Sci Sports Exerc 2001;33:208-13.

21 Anderson S, Argyros G, Magnussen H, et al. Provocation by eucapnic voluntary hyperpnoea to identify exercise induced bronchoconstriction. Br J Sports Med 2001;35:344-7.

22 Thickett K, McCoach J, Gerber J, et al. Occupational asthma caused by chloramines in indoor swimming-pool air. Eur Respir J 2002; 19:827-32

23 Nemery B, Hoet H, Nowak D. Indoor swimming pools, water chlorination and respiratory health. Eur Respir J 2002;19:790-3.

24 Mannix $E$, Farber $M$, Palange $P$, et al. Exercise-induced asthma in figure skaters. Chest 1996;109:312-5.

25 Rundell K. Pulmonary function decay in women ice hockey players: is there a relationship to ice rink air quality? Inhal Toxicol 2004;16:117-23.

26 Asthma UK. Out in the open: a true picture of asthma in the UK today. Asthma J $2001 ; 6$ (Suppl 3).

27 Anderson S, Brannan J. Long acting $\beta_{2}$-adrenoceptor agonists and exercise induced asthma. Pediatr Drugs 2004;6:1-15. 